\title{
Associations Between Herd Characteristics and Reproductive Efficiency in Dairy Herds
}

\author{
E. Löf, ${ }^{*} \dagger^{1} \mathrm{H}$. Gustafsson, $† \ddagger$ and U. Emanuelson* \\ *Department of Clinical Sciences, Division of Ruminant Medicine and Veterinary Epidemiology, Swedish University of Agricultural Sciences, \\ PO Box 7054, SE-750 07 Uppsala, Sweden \\ †Swedish Dairy Association, PO Box 210, SE-101 24 Stockholm, Sweden \\ łDivision of Comparative Reproduction, Obstetrics and Udder Health, Swedish University of Agricultural Sciences, PO Box 7054 , \\ SE-750 07 Uppsala, Sweden
}

\begin{abstract}
Dairy herds worldwide are experiencing a decline in reproductive efficiency at the same time as management methods are changing. This study aimed to investigate the extent to which herd-level characteristics were associated with reproductive performance. Data from herds using artificial insemination (AI) in the Swedish Official Milk Recording Scheme that had more than 45 cows were included in the study (total of 2,728 herds). Reproductive performance was measured as the average for each herd for the calving interval, calving to first AI interval, calving to last AI interval, number of AI per animal submitted for AI, and culling attributed to reproductive problems. Herds with mainly Swedish Holstein cows had longer calving intervals, calving to first AI, and calving to last AI compared with herds with mainly Swedish Red and White cows. Large herds had shorter calving to first AI but a greater number of AI than small herds, whereas small herds had greater culling attributed to reproductive problems than large herds. Low-yielding herds had longer calving intervals, calving to first AI, and calving to last AI and had greater culling attributed to reproductive problems than high-yielding herds, whereas herds with high milk yields had a greater number of AI than low-yielding herds. Herds with automatic milking systems had shorter calving intervals, calving to first AI, and calving to last AI and had lesser odds for culling attributed to reproductive problems when compared with herds with ordinary pipeline milking systems. Herds that used Advanced Feed Advisory Services had shorter calving to first AI but a greater number of AI and greater culling attributed to reproductive problems. Herds using TMR had longer calving intervals and calving to last AI than herds that did not. Herds with tie stalls had longer
\end{abstract}

Received December 6, 2006.

Accepted June 21, 2007.

${ }^{1}$ Corresponding author: Emma.Lof@kv.slu.se calving intervals, calving to first $\mathrm{AI}$, and calving to last $\mathrm{AI}$, and organic herds had shorter calving intervals, calving to first AI, and calving to last AI compared with conventional herds. We found that herds with do-ityourself inseminations had longer calving intervals and calving to first AI. Our study showed numerous associations between herd characteristics and reproductive performance. When allocating advisory service resources to improve reproductive performance, the focus should be on herd characteristics that are easy to influence, such as TMR and do-it-yourself inseminations.

Key words: reproductive efficiency, herd characteristic, dairy cow

\section{INTRODUCTION}

In recent decades, a decline in dairy herd reproductive efficiency has been reported from different parts of the world. Lopez-Gatius (2003) found trends of increasing infertility in dairy herds in Spain from 1991 to 2000. Several researchers in the United States have reported decreases in reproductive efficiency (Washburn et al., 2002; Rajala-Schultz and Frazer, 2003; de Vries and Risco, 2005), and similar trends of declining fertility have been demonstrated in the United Kingdom (Royal et al., 2000) and in Ireland (Roche et al., 2000). Declines in reproductive efficiency have also been observed in Sweden. In the last decade, the reproductive measurements used have shown a decreasing trend. For instance, between 1995 and 2005 the calving interval increased from 391 to $403 \mathrm{~d}$ (12.8 to $13.2 \mathrm{mo}$; N.-E. Larsson, Swedish Dairy Association, Stockholm, personal communication; Table 1).

Average milk production has increased concurrently with the decrease in reproductive efficiency. In the United States, the increase has been $20 \%$ over the last $20 \mathrm{yr}$ (Lucy, 2001), whereas between 1995 and 2005, the average annual milk production in Sweden increased by $15 \%$, representing $1,171 \mathrm{~kg}$ of ECM per cow, for cows in the Swedish Official Milk Recording Scheme (SOMRS; N.-E. Larsson, Swedish Dairy Association, 
Table 1. Reproductive measurements in all herds included in the Swedish Official Milk Recording Scheme in 1994-1995 and 2004-2005

\begin{tabular}{lcc}
\hline & $1994-1995$ & $2004-2005$ \\
Measurement & $(\mathrm{n}=12,219)$ & 403 \\
\hline Calving interval, d & 391 & 92 \\
Calving to first AI interval, d & 84 & 128 \\
Calving to last AI interval, d & 114 & 1.73 \\
AI per animal submitted for AI, n & 1.63 & 9.0 \\
Cows culled because of reproductive problems, \% & 9.1 & \\
\hline
\end{tabular}

Stockholm, personal communication). It is tempting to think that the declining reproductive efficiency and the increased milk production in dairy cows are associated, particularly when there is increasing evidence that fertility is unfavorably genetically correlated with production traits (Janson, 1980; Dematawewa and Berger, 1998; Hansen, 2000; Roxstrom et al., 2001). On the other hand, there are studies showing that milk yield in the first $60 \mathrm{~d}$ only minimally affects the chances for conception (Gröhn and Rajala-Schultz, 2000).

The structure of dairy and management practices has changed concurrently with the increase in milk production and decrease in reproductive performance. An increasing number of farmers are becoming do-ityourself (DIY) inseminators, instead of using professional AI technicians; the number of cows per farm has continued to increase (Washburn et al., 2002); cows are increasingly being held in free stalls (Bielfeldt et al., 2006); and the use of automatic milking systems is increasing (Hyde and Engel, 2002). It is likely that these changes affect dairy cow reproductive performance and not only the milk yield. However, it is unclear how the effects of these factors compare with the effect of increasing milk yield. A clear picture of the effects is important to allocate specialized advisory services more cost effectively. The present study aimed at investigating whether and to what extent herd-level characteristics were associated with reproductive performance.

\section{MATERIALS AND METHODS}

\section{Source of Information}

In this cross-sectional study, we studied Swedish dairy herds registered in the SOMRS that used AI, and data were available from September 1, 2004, to August 31,2005 . Registrations from a total of 7,241 farms were available, representing $86 \%$ of all Swedish dairy herds. All farms that had more than 45 milking cows, on average, during the period were included in the study, totaling 2,728 farms. Registry data were extracted from the SOMRS, and reproductive measurements were obtained for each herd as an average for the study period.
This was done in such a way that all values for the desired measurement, for all animals that had a value for the measurement during the study period, were summed and then divided by the number of animals that had a measurement for that particular measure for each herd. Other factors were obtained from the SOMRS, such as the geographic region, breed composition of the herd, herd size, and 365-d ECM yield. Information on whether the farmer used DIY inseminations and whether the herd used an Advanced Feed Advisory Service was acquired from the Swedish Dairy Association. The Swedish Dairy Association provided us with additional data on herd characteristics, such as type of milking system (pipeline, automatic or robotic, and parlors or rotaries), feeding system (TMR or not specified), and type of housing (tie stall or free stall), which had been collected in a survey of all dairy farms in the SOMRS from 2004. In addition to the information from the survey, KRAV, the official Swedish organic certifying organization, reported the organically managed herds.

\section{Outcome Variables}

The reproductive performance measurements of interest were calving interval, calving to first AI interval, calving to last AI interval, number of AI per animal submitted for AI and culling attributed to reproductive problems. Calving interval, calving to first AI, calving to last $\mathrm{AI}$, and the number of $\mathrm{AI}$ were measured on a continuous scale. Calving interval, calving to first AI, and calving to last AI were measured in days, and number of AI was measured as the count of inseminations. Culling attributed to reproductive problems was measured as the proportion of cows in the herd. Calving interval was calculated only for multiparous cows in the herd, and calving to first and last AI were calculated for all cows in the herd. No information on conception dates was available; therefore, days from calving to last AI was used as a proxy for calving to conception or days open (Seykora and McDaniel, 1983, Plaizier et al., 1997). The number of AI was calculated as the sum of all inseminations divided by the number of animals 
Table 2. Overall median, 25th percentile, and 75th percentile for reproductive and production measurements in the Swedish dairy herds studied

\begin{tabular}{lccc}
\hline Measurement & Median & 25th & 75 th \\
\hline Calving interval, d & 400 & 386 & 417 \\
Calving to first AI interval, d & 89 & 79 & 102 \\
Calving to last AI interval, d & 125 & 112 & 141 \\
AI per animal submitted for AI, n & 1.76 & 1.57 & 1.97 \\
Cows culled because of reproductive problems, \% & 8.6 & 4.8 & 13 \\
365-d ECM yield, kg & 9,234 & 8,529 & 9,945 \\
Herd size, n & 65 & 53 & 89 \\
\hline
\end{tabular}

submitted for AI in the herd. Culling is reported to the SOMRS by the farmer, who can choose up to 3 reasons from 23 different codes to identify the reason why the cow was culled. Two codes were related to fertility: impaired fertility and not pregnant. Descriptive statistics for the different outcomes are shown in Table 2. To remove outliers caused by recording errors, the measurements for calving interval, number of AI, and culling attributed to reproductive problems were censored at the 99th percentile. For calving to first $\mathrm{AI}$ and calving to last AI, this was done in a similar way, but here the values below the first percentile were also removed.

\section{Predictor Variables}

The predictor variables used to identify associations with reproductive measurements were geographic region, divided into 8 different local livestock organizations; breed composition of herd, divided into $>80 \%$ Swedish Red and White, $>80 \%$ Swedish Holstein, or mixed and other breeds; herd size, categorized according to thirds (i.e., 45 to 56.7 cows, between 56.7 and 76.6 cows, or more than 76.6 cows); 365-d ECM yield, categorized according to thirds (i.e., yield up to 8,780 , between 8,780 and 9,672 , or more than 9,672 ); milking system, divided into pipeline, automatic, or parlor and rotaries; TMR, dichotomized into yes or no; stall type, divided in free stall or tie stall; organic, dichotomized into yes or no; DIY inseminations, dichotomized into yes or no; and Advanced Feed Advisory Service, dichotomized into yes or no. Descriptive statistics for milk yield and herd size are shown in Table 2 . The distribution of farms in the different predictor variables is shown in Table 3.

\section{Data Analysis}

The associations between the predictor variables and the outcome variables of calving interval, calving to first AI interval, calving to last AI interval, and number of AI per animal submitted for AI were analyzed by linear regression models. The association between the predictor variables and the outcome variable of culling attributed to reproductive problems was analyzed by a logistic regression model. Model building was by backward stepwise elimination of main effects, with $P<0.2$ as the exclusion and reentering criterion. Biologically relevant interactions were subsequently added to the model and the backward stepwise elimination process was continued but with $P<0.05$ as the exclusion and reentering criterion. In the final model, all remaining effects were significant at $P<0.05$. To evaluate homoscedasticity of the variance for the linear regression models, the standardized residuals were plotted against the predicted values. The normality of the residuals was assessed visually by a normal probability plot. No problems in homoscedasticity or normality were found. All statistical analyses were performed by using the software package SAS, version 9.1 (SAS Institute, 2004).

\section{RESULTS}

\section{Calving Interval}

Significant results on calving interval are given in Table 4 . The calving interval was shorter $(P<0.001)$ in herds that mainly had Swedish Red and White cows compared with herds that mainly had Swedish Holstein cows. The calving interval was also shorter $(P=0.04)$ in organically managed herds compared with conventionally managed herds. The calving interval was longer $(P=0.04)$ in herds that used TMR compared with herds that did not. The calving interval was also longer $(P<0.001)$ in herds with tie stalls compared with herds with free stalls. The calving interval was shorter $(P=0.01)$ in herds with automatic milking compared with herds with ordinary pipeline milking. The comparison showed the same results for automatic milking and milking parlors or rotaries $(P=0.02)$. The calving interval was longer $(P<0.001)$ in herds that had DIY inseminations than in herds that did not use DIY inseminations. The calving interval was shorter $(P<0.001)$ in high-yielding herds compared with lowyielding herds. 
Table 3. Distribution of the studied Swedish dairy herds for different predictor variables

\begin{tabular}{llr}
\hline Predictor variable & \multicolumn{1}{c}{ Class } & Herds, n \\
\hline Geographic region & $\mathrm{A}$ & 291 \\
& $\mathrm{~B}$ & 614 \\
& $\mathrm{C}$ & 139 \\
& $\mathrm{D}$ & 213 \\
& $\mathrm{E}$ & 823 \\
& $\mathrm{~F}$ & 91 \\
& $\mathrm{G}$ & 417 \\
Breed composition of the herd & $\mathrm{H}$ & 140 \\
& $>80 \%$ Swedish Red and White & 653 \\
Herd size & $>80 \%$ Swedish Holstein & 807 \\
& Mixed or other breeds & 1,268 \\
& Up to 56.7 & 907 \\
$365-d$ ECM yield, kg & 56.7 to 76.6 & 910 \\
& $>76.6$ & 911 \\
Milking system & $1:$ up to 8,780 & 891 \\
& $2: 8,780$ to 9,672 & 894 \\
TMR & $3:>9,672$ & 893 \\
& Pipeline & 1,769 \\
Stall type & Robotic & 187 \\
Organic & Parlor or rotaries & 772 \\
& Yes & 357 \\
Do-it-yourself inseminations & No & 2,371 \\
Advanced Feed Advisory Service & Tie stall & 1,738 \\
& Free stall & 990 \\
& Yes & 170 \\
& No & 2,558 \\
& Yes & 1,025 \\
& No & 1,703 \\
& Yes & 710 \\
& No & 2,018 \\
\hline
\end{tabular}

\section{Calving to First Al Interval}

Significant results on calving to first AI interval are given in Table 5. Calving to first AI was shorter $(P<$ 0.001) in herds that mainly had Swedish Red and White cows compared with herds that mainly had Swedish
Holstein cows. Calving to first AI was also shorter $(P=$ 0.05 ) in organically managed herds compared with conventionally managed herds. In herds that used an Advanced Feed Advisory Service, calving to first AI was shorter $(P=0.01)$ when compared with herds that did not use an Advanced Feed Advisory Service. Calving

Table 4 Significant associations between calving interval (d) and predictor variables assessed by a linear regression model $^{1}$

\begin{tabular}{llccc}
\hline \multirow{2}{*}{ Predictor variable } & \multicolumn{1}{c}{ Class } & LSM & $\begin{array}{c}95 \% \text { confidence } \\
\text { interval }\end{array}$ & $P$-value \\
\hline Breed composition of herd & $>80 \%$ Swedish Red and White & 391.6 & $388.8-394.5$ & $<0.001$ \\
& $>80 \%$ Swedish Holstein & 412.1 & $409.4-414.8$ & \\
365-d ECM yield, kg & Mixed and other breeds & 398.8 & $396.4-401.3$ & \\
& $<8,780$ & 406.2 & $403.7-408.7$ & $<0.001$ \\
Milking system & 8,780 to 9,672 & 399.5 & $396.9-402.1$ & \\
& $>9,672$ & 396.8 & $394.1-399.6$ & \\
TMR & Pipeline & 403.1 & $400.3-405.9$ & 0.02 \\
& Robotic & 397.5 & $393.7-401.4$ & \\
Stall type & Parlor or rotaries & 401.9 & $399.1-404.7$ & \\
\multirow{2}{*}{ Organic } & Yes & 402.4 & $399.2-405.5$ & 0.04 \\
& No & 399.3 & $397.2-401.5$ & \\
Do-it-yourself inseminations & 405.5 & $402.4-408.6$ & $<0.001$ \\
& Tie stall & 396.2 & $393.7-398.7$ & \\
& Free stall & 399 & $395.3-402.8$ & 0.04 \\
& Yes & 402.7 & $401.0-404.4$ & \\
& No & 402.6 & $400.1-405.1$ & $<0.001$ \\
\hline
\end{tabular}

${ }^{1}$ Results are controlled for geographic region and are presented as the LSM, confidence interval, and probability values. 
Table 5. Significant associations between calving to first AI interval (d) and predictor variables assessed by a linear regression model $^{1}$

\begin{tabular}{|c|c|c|c|c|}
\hline Predictor variable & Class & LSM & $\begin{array}{l}95 \% \text { confidence } \\
\text { interval }\end{array}$ & $P$-value \\
\hline \multirow[t]{3}{*}{ Breed composition of herd } & $>80 \%$ Swedish Red and White & 83.3 & $81.1-85.5$ & \multirow[t]{3}{*}{$<0.001$} \\
\hline & $>80 \%$ Swedish Holstein & 96.1 & $94-98.2$ & \\
\hline & Mixed or other breeds & 88.1 & $86.1-90$ & \\
\hline \multirow[t]{3}{*}{ Herd size } & $<56.7$ & 90.3 & $88.2-92.4$ & \multirow[t]{3}{*}{0.04} \\
\hline & 56.7 to 76.6 & 89.2 & $87.3-91.1$ & \\
\hline & $>76.6$ & 87.9 & $85.8-89.9$ & \\
\hline \multirow[t]{3}{*}{ 365-d ECM yield, kg } & $<8,780$ & 94.1 & $92.1-96.0$ & \multirow[t]{3}{*}{$<0.001$} \\
\hline & 8,780 to 9,672 & 87.1 & $85.1-89.1$ & \\
\hline & $>9,672$ & 86.2 & $84.1-88.4$ & \\
\hline \multirow[t]{3}{*}{ Milking system } & Pipeline & 90.4 & $88.3-92.5$ & \multirow{3}{*}{$<0.001$} \\
\hline & Robotic & 85.6 & $82.5-88.6$ & \\
\hline & Parlor or rotaries & 91.4 & $89.1-93.6$ & \\
\hline \multirow[t]{2}{*}{ Stall type } & Tie stall & 90.8 & $88.4-93.2$ & \multirow[t]{2}{*}{0.02} \\
\hline & Free stall & 87.5 & $85.5-89.5$ & \\
\hline \multirow[t]{2}{*}{ Organic } & Yes & 87.7 & $84.7-90.6$ & \multirow[t]{2}{*}{$<0.05$} \\
\hline & No & 90.6 & $89.3-91.8$ & \\
\hline \multirow[t]{2}{*}{ Do-it-yourself inseminations } & Yes & 89.9 & $88-91.9$ & \multirow[t]{2}{*}{0.03} \\
\hline & No & 88.3 & $86.5-90.2$ & \\
\hline \multirow{2}{*}{ Advanced Feed Advisory Service } & Yes & 88.1 & $86-90.2$ & \multirow{2}{*}{0.01} \\
\hline & No & 90.2 & $88.4-92$ & \\
\hline
\end{tabular}

${ }^{1}$ Results are controlled for geographic region and are presented as the LSM, confidence interval, and probability values.

to first AI was longer $(P=0.02)$ in herds with tie stalls compared with herds with free stalls. Calving to first AI was shorter $(P<0.01)$ in herds with automatic milking systems when compared with herds with ordinary pipeline milking, and the same was shown between automatic milking and milking parlors or rotaries $(P<$ 0.001). Herds that used DIY inseminations had longer calving to first $\mathrm{AI}(P=0.03)$ compared with herds that were using professional inseminators. High-yielding herds had shorter calving to first AI $(P<0.001)$ than low-yielding herds. Larger herds had shorter calving to first $\mathrm{AI}(P=0.01)$ than smaller herds.

\section{Calving to Last Al Interval}

Significant results on calving to last AI interval are given in Table 6. Herds that mainly had Swedish Red and White cows had shorter calving to last AI $(P<$ 0.001) compared with herds that mainly had Swedish Holstein cows. Calving to last AI was shorter $(P<0.01)$ in organic herds compared with herds that were conventionally managed. Calving to last AI was longer $(P<$ 0.01) in herds that used TMR compared with herds that did not. Herds that had tie stalls had longer calving to last $\mathrm{AI}(P<0.001)$ compared with herds with free stalls. Calving to last AI was shorter $(P<0.01)$ in herds with automatic milking systems when compared with herds with ordinary pipeline milking, and the same was shown between automatic milking and milking parlors or rotaries $(P<0.001)$. Calving to last AI was also shorter $(P<0.001)$ in high-yielding herds compared with low-yielding herds.

\section{Number of Al per Animal Submitted for Al}

Significant results for the number of AI per animal submitted for AI are given in Table 7. The number of AI was greater $(P=0.001)$ in herds that used an Advanced Feed Advisory Service compared with herds that did not. Larger herds had a greater $(P=0.01)$ number of AI than small herds. The interaction between breed composition of the herd and DIY showed that herds with mainly Swedish Red and White cows that used DIY inseminations had a greater number of AI ( $P$ $<0.01$ ) when compared with herds with mainly Swedish Holstein cows and DIY inseminations. The interaction between breed composition of the herd and stall type showed that there was an overall difference between the 2 stall types, with a greater number of $\mathrm{AI}(P<0.001$, $P=0.05$, and $P<0.001$, for Swedish Red and White, Swedish Holstein, and mixed or other herds, respectively) in tie stalls compared with free stalls. The herds with mainly Swedish Red and White cows had a greater $(P<0.001)$ number of AI in tie stalls compared with Swedish Holsteins in tie stalls. There was no difference between the different breeds in free stalls. The interaction between 365-d milk yield and stall type showed that there was an overall difference between the 2 stall types, with a greater number of $\mathrm{AI}(P<0.001, P<0.001$, and $P<0.001)$ in tie stalls compared with free stalls. 
Table 6. Significant associations between calving to last AI interval (d) and predictor variables assessed by a linear regression model $^{1}$

\begin{tabular}{llccc}
\hline \multirow{2}{*}{ Predictor variable } & \multicolumn{1}{c}{ Class } & LSM & $\begin{array}{c}95 \% \text { confidence } \\
\text { interval }\end{array}$ & $P$-value \\
\hline Breed composition of herd & $>80 \%$ Swedish Red and White & 115.5 & $112.9-118.3$ & $<0.001$ \\
& $>80 \%$ Swedish Holstein & 133.8 & $131.2-136.4$ & \\
365-d ECM yield, kg & Mixed or other breeds & 123.3 & $120.9-125.6$ & \\
& $<8,780$ & 128.2 & $125.8-130.6$ & $<0.001$ \\
Milking system & 8,780 to 9,672 & 121.8 & $119.3-124.3$ & \\
& $>9,672$ & 122.6 & $120.0-125.2$ & \\
TMR & Pipeline & 126.8 & $124.2-129.5$ & $<0.001$ \\
& Robotic & 119.7 & $116.1-123.4$ & \\
Stall type & Parlor or rotaries & 126.1 & $123.3-128.8$ & \\
& Yes & 126.2 & $123.1-129.2$ & $<0.01$ \\
Organic & No & 122.3 & $120.2-124.3$ & \\
& Tie stall & 128.8 & $125.8-131.7$ & $<0.001$ \\
& Free stall & 119.7 & $117.2-122.1$ & \\
& Yes & 121.6 & $118.3-125.4$ & $<0.01$ \\
\hline
\end{tabular}

${ }^{1}$ Results are controlled for geographic region and are presented as the LSM, confidence interval, and probability values.

Table 7. Significant associations between the number of AI per animal submitted for AI and predictor variables assessed by a linear regression model $^{1}$

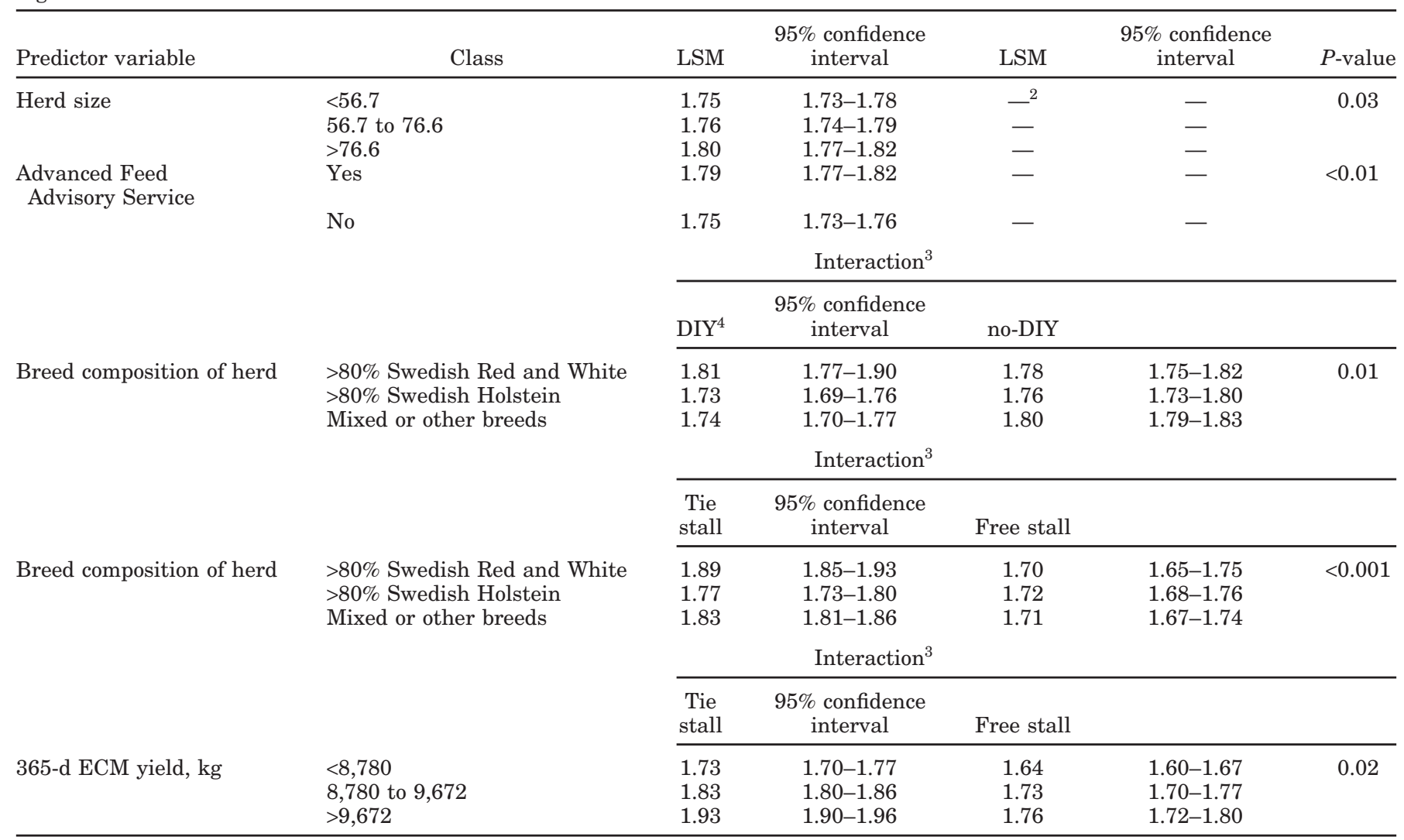

\footnotetext{
${ }^{1}$ Results are controlled for geographic region and are presented as the LSM, confidence interval, and probability values.
}

${ }^{2}$ Indicates not applicable.

${ }^{3}$ Denotes an interaction between main effects in the model.

${ }^{4}$ Do-it-yourself inseminations. 
Table 8. Significant associations between culling attributed to reproductive problems and predictor variables assessed by a logistic regression model $^{1}$

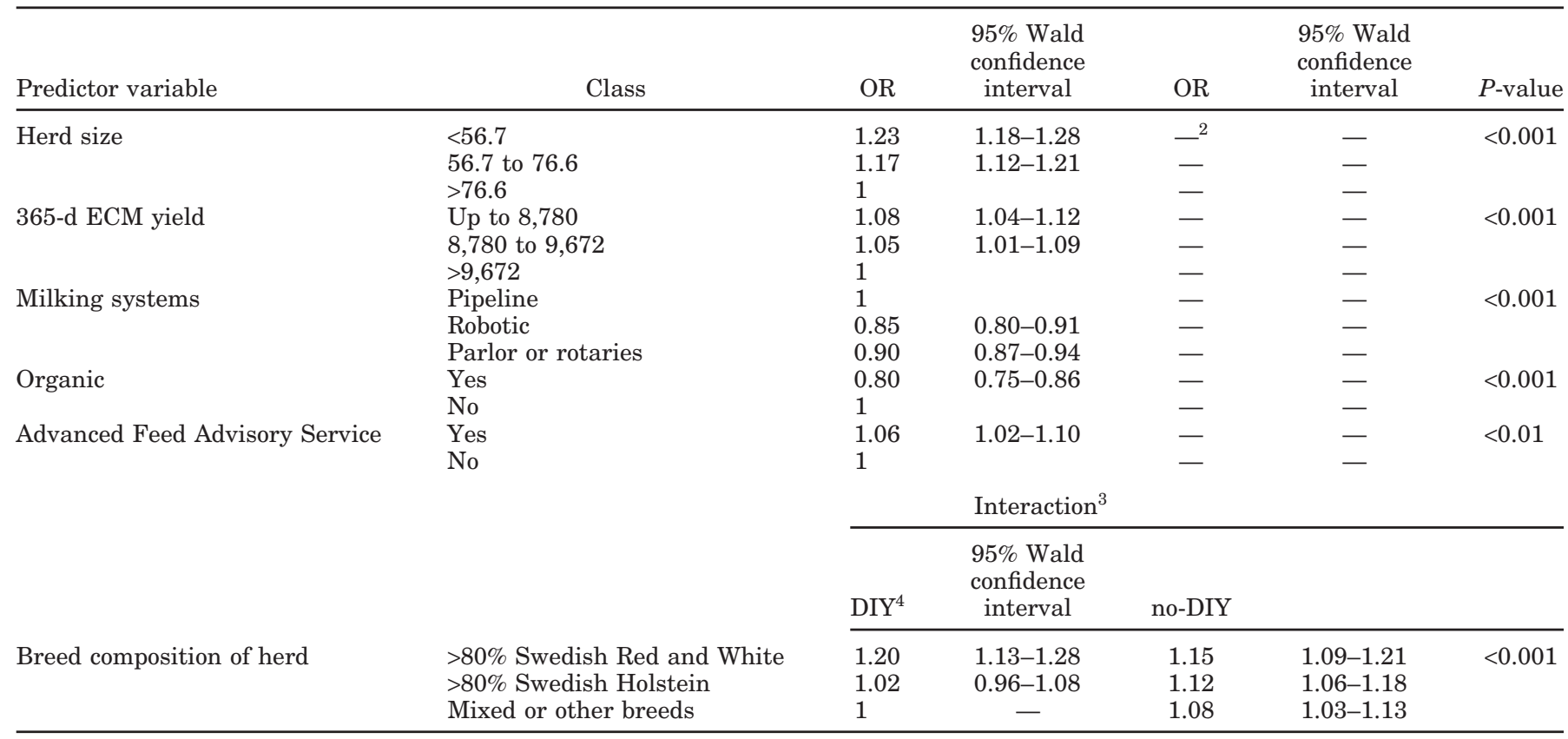

${ }^{1}$ Results are controlled for geographic region and are presented as the odds ratios (OR), Wald confidence interval and probability values.

${ }^{2}$ Indicates not applicable.

${ }^{3}$ Denotes an interaction between main effects in the model.

${ }^{4}$ Do-it-yourself inseminations.

If the herd was high yielding and had free stalls, the number of AI was greater $(P<0.001)$ compared with low-yielding herds in free stalls. The same was seen for herds with tie stalls, with high-yielding herds having a greater $(P<0.001)$ number of $\mathrm{AI}$ than low-yielding herds.

\section{Culling Attributed to Reproductive Problems}

Significant results on culling attributed to reproductive problems are given in Table 8. The odds for culling attributed to reproductive problems were greater $(P=$ 0.02 and $P<0.001)$ in small-sized herds than in both medium- and large-sized herds. Low-yielding herds had greater $(P<0.001)$ odds for culling attributed to reproductive problems than high-yielding herds, as had medium-yielding herds $(P<0.001)$, but there was no significant difference between low- and medium-yielding herds. Herds with automatic milking systems had smaller $(P<0.001)$ odds for culling attributed to reproductive problems than herds with pipeline milking, and herds with parlors or rotaries also had smaller $(P<$ 0.001 ) odds for culling attributed to reproductive problems compared with herds with pipeline milking. The odds for culling attributed to reproductive problems were smaller $(P<0.001)$ in organic herds compared with nonorganic herds. Herds that were using an Advanced Feed Advisory Service had greater $(P=0.001)$ odds for culling attributed to reproductive problems than herds that did not.

The interaction between breed composition of the herd and DIY inseminations showed that the odds for culling attributed to reproductive problems were greater $(P<0.001)$ in Swedish Red and White-dominated herds than in herds that mainly had Swedish Holstein cows if they used DIY inseminations, whereas there was no difference if they did not use DIY inseminations. In herds with mainly Swedish Holstein cows, the odds for culling attributed to reproductive problems were greater $(P<0.001)$ for herds not using DIY inseminations than in herds using DIY inseminations, but no differences were found for herds with mainly Swedish Red and White cows.

\section{DISCUSSION}

\section{Reproductive Performance Measurements}

We studied the traditional reproductive measurements used by the $\mathrm{AI}$ industry for monitoring reproductive status and trends in dairy herds. Calving to first AI interval and calving to last AI interval are components of the calving interval and, hence, are interre- 
lated with each other. This can be observed in our study, in which the interval measurements followed each other within different herd characteristics; for example, calving interval, calving to first AI, and calving to last AI were all longer in herds with tie stalls compared with herds with free stalls.

We used calving to last $\mathrm{AI}$ as a proxy for calving to conception interval or days open. It is important to consider that, in our data set, the last insemination does not necessarily mean conception. The calving interval measurement requires that a cow has calved twice, and can consequently not be calculated among primiparous cows or cows culled before the next calving. The interval measurements are highly dependent not only on the ability to conceive, but also on the farm policy for when to start breeding after calving (i.e., voluntary waiting period) and on the efficiency of heat detection. In addition, these measurements can be distorted by the farmers' decisions on culling or not to breed.

The number of AI per animal submitted for AI reflects the conception rate and thus the contributions needed for a certain calving to last AI interval. Similar to calving to first AI interval and to last AI interval, the number of AI is calculated on all inseminated animals and not only on pregnant animals, and cannot be translated directly into the conception rate. This measurement is highly dependent on management factors and practices at the dairy. A small number of AI can reflect a high conception rate but can also be achieved by failure to observe heat, which complicates evaluation of the measurement. A large number of AI could be a sign of poor fertility, but may also reflect the efforts made to impregnate the cows. This can be seen in our study, in which short interval measurements for a certain management factor sometimes occurred with a greater number of AI; that is, calving interval, calving to first AI, and calving to last AI were shorter in high-yielding herds, but the number of AI was greater in high-yielding herds compared with low-yielding herds.

Causes for culling in the SOMRS are reported by the farmer and may contain a certain degree of subjectivity. It is possible that nonpregnant animals inseminated one time only, but with low production and poor feet, were reported as "culled due to not pregnant" instead of the more obvious causes-low production and poor feet. However, studies have shown good agreement between reproduction-related reasons for culling and observations on reproductive measurements (Roxstrom and Strandberg, 2002), thus indicating that the causespecific reasons are relatively accurate.

With all measurements used, several disadvantages must be considered when interpreting results (Fetrow et al., 2007). Short interval measurements, a small number of AI, and a small proportion of cows culled for infertility in a herd are evidence of good reproductive performance and are closely related to herd economy (Esslemont, 2003).

\section{Associations Between Herd Characteristics and Reproductive Efficiency}

Breed Composition of the Herd. Herds with mainly Swedish Holstein cows had a longer calving interval and calving to the first and last AI intervals compared with herds with a majority of Swedish Red and White cows. The interaction between herd breed composition and stall type showed that herds with mainly Swedish Red and White cows had a greater number of AI per cow submitted for AI than herds with mainly Swedish Holstein cows. These findings disagreed with those by Oltenacu et al. (1991), who observed that first-lactation Swedish Holstein cows had better reproduction than Swedish Red and White cows. This is possibly an effect of the different genetic makeup evolving between the 2 breeds during the last 15 yr. Fertility has been taken into account in the national breeding program for both breeds, but it has been less effective for the Swedish Holstein breed because of substantial importation of foreign genetic material. The greater number of AI for herds with mainly Swedish Red and White cows may reflect better estrous expression, leading to more estruses observed. In our study, the odds for culling attributed to reproductive problems were greater in Swedish Red and White herds than in Swedish Holstein herds, and a greater culling rate may give shorter intervals (Plaizier et al., 1997), but this was found only in herds using DIY inseminations.

Herd Size. Large herds had shorter calvings to the first AI interval but a greater number of AI per animal submitted for AI than small herds, whereas the smaller herds had greater odds for culling attributed to reproductive problems than large herds. This indicated that reproductive efficiency may be better in large herds, which is contrary to the results of Fahey et al. (2002). Those authors reported that the calving rate was lesser in large herds, thus implying lesser reproductive efficiency in large herds. An explanation for the greater number of AI in large herds in our study could be that it was easier to control fewer cows, and therefore one does not need as many inseminations to impregnate cows in small herds. On the other hand, large herds may have had better estrous detection, and therefore more cows were inseminated.

Milk Yield. Higher milk yield has been reported to have a negative influence on fertility in dairy cows (Dematawewa and Berger, 1998; Hansen, 2000). In our study, we observed that low-yielding herds had a longer calving interval, calving to first and last AI intervals, 
and greater odds for culling attributed to reproductive problems than did high-yielding herds. Herds with high milk yields had a greater number of AI per animal submitted for AI than the low-yielding herds. It is important to remember that these results are at the herd level and that such associations may not necessarily hold on the individual animal level. It is easier to achieve a high herd average 365-d ECM yield, which was our measurement of milk yield, when the reproductive performance at the herd level is good. Windig et al. (2005) found that herds with high average yields had shorter calving to first AI intervals but that within herds, cows with high production had longer calving to first AI intervals. Our results based on data from 2005 are basically the same as reported by Emanuelson and Oltenacu (1998) based on Swedish data from 1983 to 1989, implying a better reproductive performance in general in high-producing herds compared with lowproducing herds.

Milking Systems. Herds with automatic milking systems had a shorter calving interval and calving to first and last AI intervals and had smaller odds for culling attributed to reproductive problems when compared with ordinary pipeline milking herds. It has been suggested that farmers can reduce the calving interval and calving to first and last AI if infertile cows are culled (Plaizier et al., 1997). However, our results showed that a high culling rate was not necessary to achieve short intervals. When studying the effects of automatic milking on fertility, Kruip et al. (2002) found that automatic milking was associated with an increase in the number of days to first service. Recent studies have also indicated that the first visually detected estrus is delayed by increasing the milking frequency from 2 to 4 times a day (Blevins et al., 2006). This is in contrast to the findings in our study and may be explained by the fact that robots are generally adjusted to allow a maximum of 3 milkings per day.

TMR and Advanced Feed Advisory Services. Energy supply affects how well the cows perform, and negative energy balance has been shown to negatively affect fertility (Butler, 2000). In an Advanced Feed Advisory Service, the cows are individually evaluated and rations are set to the individual animal's requirement based on production level and lactation stage. Total mixed rations are not fed to the individual cow; therefore, there could be cows whose energy requirements are not met. In our study, herds that used an Advanced Feed Advisory Service had a shorter calving to first AI interval but a greater number of AI per animal submitted for AI and greater odds for culling attributed to reproductive problems. Herds using TMR had a longer calving interval and calving to last AI interval than herds that did not use TMR. It has been observed by feed advisers in Sweden that some cows in TMR systems are obese at calving if the system is not properly managed. Overconditioned cows are known to eat less and have a lower DMI after calving than lean cows (Garnsworthy and Topps, 1982). These cows will experience a greater loss in body condition, which leads to a higher risk for anovulatory anestrus.

Barn and Stall Design. There is a trend toward more free stalls, and more herds are using automatic milking systems. In our study, we found that herds using tie stalls had a longer calving interval, calving to first AI interval, and calving to last AI interval. The interactions between breed composition of the herd and stall type and between milk yield and stall type generally showed a greater number of AI per animal submitted for AI for herds with tie stalls. Other studies have revealed that the reproductive performance differs in different housing systems. Petersson et al. (2006) demonstrated that the interval between calving and first ovulation and estrus is shorter in free stalls compared with tie stalls, enabling an earlier insemination in freestall herds. Valde et al. (1997) showed that herds with tie stalls had a lesser fertility status index than did herds with free stalls, implying that cows in free stalls have better reproductive efficiency.

Organic Classification of the Farm. For the calving interval and calving to first and last AI intervals, organic herds had shorter intervals compared with conventional herds. These findings are in contrast to those of Reksen et al. (1999), in which reproductive efficiency was impaired in organically managed herds in comparison with conventionally managed dairy herds. Organic herds tended to have less milk production than conventional herds, which could be beneficial for reproductive efficiency, but in our study the results were adjusted for milk yield. However, it is difficult to compare results between countries for organic herds because the different regulations for organic farming lead to different feeding or management regimens, which affect the cows differently. This makes it less reliable to draw a general conclusion about organic herds because this may vary from country to country. Earlier studies in Sweden focusing on general health rather than fertility have shown that organic farmers are a diverse group, but in general, organic herds have a lower incidence of diseases and a good standard of animal health and welfare, which supports our findings (Hamilton et al., 2002).

DIY Inseminations. In Sweden, there is a trend for more farmers to perform DIY inseminations instead of using professional AI technicians. In our study, herds that were using DIY inseminations had longer calving and calving to first AI intervals. If the herd used DIY inseminations and had mainly Swedish Red and White cows, the number of AI per animal submitted for AI and 
the odds for culling attributed to reproductive problems were greater. These results show that the change to DIY inseminations could have negative effects on reproductive performance, which is in agreement with a study by McCoy et al. (2006), who suggested that poor DIY techniques contributed to impaired reproductive performance on dairy farms in Northern Ireland. In contrast, Buckley et al. (2003) recorded no difference between farmers and AI technicians in pregnancy rates to first inseminations in well-managed herds. Our results, however, indicate that DIY inseminations must be regarded as a risk factor for decreasing reproductive efficiency and that herds using DIY insemination should be closely supervised. Farmers could be offered refresher courses to eliminate negative factors causing suboptimal conception rates.

\section{CONCLUSIONS}

Our study showed numerous associations between herd characteristics and reproductive performance. Even though most effects were numerically small, they showed that changes in management may be part of the explanation for the observed trend in reproductive performance. Moreover, some recent changes in the structure of how herds are managed were favorable (e.g., more free stalls and automatic milking), whereas others were unfavorable (e.g., TMR and DIY). The overall effect, however, was difficult to assess without proper information on the extent to which these herd characteristics have changed. When allocating advisory service resources to improve reproductive performance, the focus should be on herd characteristics that are easy to influence, such as TMR and DIY inseminations.

\section{ACKNOWLEDGMENT}

This study was financially supported by The Swedish Farmers' Foundation for Agricultural Research.

\section{REFERENCES}

Bielfeldt, J. C., K.-H. Tolle, R. Badertscher, and J. Krieter. 2006. Longevity of Swiss Brown cattle in different housing systems in Switzerland. Livest. Sci. 101:134-141.

Blevins, C. A., J. E. Shirley, and J. S. Stevenson. 2006. Milking frequency, estradiol cypionate, and somatotropin influence lactation and reproduction in dairy cows. J. Dairy Sci. 89:4176-4187.

Buckley, F., J. Mee, K. O'Sullivan, R. Evans, D. Berry, and P. Dillon. 2003. Insemination factors affecting the conception rate in seasonal calving Holstein-Friesian cows. Reprod. Nutr. Dev. 43:543-555.

Butler, W. R. 2000. Nutritional interactions with reproductive performance in dairy cattle. Anim. Reprod. Sci. 60-61:449-457.

Dematawewa, C. M. B., and P. J. Berger. 1998. Genetic and phenotypic parameters for 305-day yield, fertility, and survival in Holsteins. J. Dairy Sci. 81:2700-2709. de Vries, A., and C. A. Risco. 2005. Trends and seasonality of reproductive performance in Florida and Georgia dairy herds from 1976 to 2002. J. Dairy Sci. 88:3155-3165.

Emanuelson, U., and P. A. Oltenacu. 1998. Incidences and effects of diseases on the performance of Swedish dairy herds stratified by production. J. Dairy Sci. 81:2376-2382.

Esslemont, R. J. 2003. The costs of poor fertility and what to do about reducing them. Cattle Pract. 11:237-250.

Fahey, J., K. O'Sullivan, J. Crilly, and J. F. Mee. 2002. The effect of feeding and management practices on calving rate in dairy herds. Anim. Reprod. Sci. 74:133-150.

Fetrow, J., S. Stewart, S. Eicker, and P. Rapnicki. 2007. Reproductive health programs for dairy herds: Analysis of records for assessment of reproductive performance. Pages 473-490 in Current Therapy in Large Animal Theriogenology. 2nd ed. R. S. Youngquist and W. R. Threlfall, ed. Saunders Elsevier, St. Louis, MO.

Garnsworthy, P. C., and J. H. Topps. 1982. The effect of body condition of dairy cows at calving on their food intake and performance when given complete diets. Anim. Prod. 35:113-119.

Gröhn, Y. T., and P. J. Rajala-Schultz. 2000. Epidemiology of reproductive performance in dairy cows. Anim. Reprod. Sci. 6061:605-614.

Hamilton, C., I. Hansson, T. Ekman, U. Emanuelson, and K. Forslund. 2002. Health of cows, calves and young stock on 26 organic dairy herds in Sweden. Vet. Rec. 150:503-508.

Hansen, L. B. 2000. Consequences of selection for milk yield from a geneticist's viewpoint. J. Dairy Sci. 83:1145-1150.

Hyde, J., and P. Engel. 2002. Investing in a robotic milking system: A Monte Carlo simulation analysis. J. Dairy Sci. 85:2207-2214.

Janson, L. 1980. Studies on fertility traits in Swedish dairy cattle. Part II: Genetic parameters. Acta Agric. Scand. 30:427-436.

Kruip, T. A. M., H. Morice, M. Robert, and W. Ouweltjes. 2002. Robotic milking and its effect on fertility and cell counts. J. Dairy Sci. 85:2576-2581.

Lopez-Gatius, F. 2003. Is fertility declining in dairy cattle? A retrospective study in northeastern Spain. Theriogenology 60:89-99.

Lucy, M. C. 2001. Reproductive loss in high-producing dairy cattle: Where will it end? J. Dairy Sci. 84:1277-1293.

McCoy, M. A., D. R. Mackey, A. W. Gordon, B. W. Kennedy, H. W. J. Edgar, and C. S. Mayne. 2006. Fertility results after do-ityourself and commercial company artificial insemination in dairy herds in Northern Ireland. Vet. Rec. 159:119-121.

Oltenacu, P. A., A. Frick, and B. Lindhe. 1991. Relationship of fertility to milk yield in Swedish cattle. J. Dairy Sci. 74:264-268.

Petersson, K.-J., E. Strandberg, H. Gustafsson, and B. Berglund. 2006. Environmental effects on progesterone profile measures of dairy cow fertility. Anim. Reprod. Sci. 91:201-214.

Plaizier, J. C. B., G. J. King, J. C. M. Dekkers, and K. Lissemore. 1997. Estimation of economic values of indices for reproductive performance in dairy herds using computer simulation. J. Dairy Sci. 80:2775-2783.

Rajala-Schultz, P. J., and G. S. Frazer. 2003. Reproductive performance in Ohio dairy herds in the 1990s. Anim. Reprod. Sci. $76: 127-142$

Reksen, O., A. Tverdal, and E. Ropstad. 1999. A comparative study of reproductive performance in organic and conventional dairy husbandry. J. Dairy Sci. 82:2605-2610.

Roche, J. F., D. Mackey, and M. D. Diskin. 2000. Reproductive management of postpartum cows. Anim. Reprod. Sci. 60-61:703-712.

Roxstrom, A., and E. Strandberg. 2002. Genetic analysis of functional, fertility-, mastitis-, and production-determined length of productive life in Swedish dairy cattle. Livest. Prod. Sci. 74:125-135.

Roxstrom, A., E. Strandberg, B. Berglund, U. Emanuelson, and J. Philipsson. 2001. Genetic and environmental correlations among female fertility traits and milk production in different parities of Swedish Red and White dairy cattle. Acta Agric. Scand. A., Anim. Sci. 51:7-14.

Royal, M. D., A. O. Darwash, A. P. E. Flint, R. Webb, J. A. Woolliams, and G. E. Lamming. 2000. Declining fertility in dairy cattle: Changes in traditional and endocrine parameters of fertility. Anim. Sci. 70:487-501. 
SAS Institute. 2004. SAS Software. 9.1 ed. SAS Institute Inc., Cary, NC.

Seykora, A. J., and B. T. McDaniel. 1983. Heritabilities and correlations of lactation yields and fertility for Holsteins. J. Dairy Sci. 66:1486-1493.

Valde, J. P., D. W. Hird, M. C. Thurmond, and O. Osteras. 1997. Comparison of ketosis, clinical mastitis, somatic cell count, and reproductive performance between free stall and tie stall barns in
Norwegian dairy herds with automatic feeding. Acta Vet. Scand. 38:181-192.

Washburn, S. P., W. J. Silvia, C. H. Brown, B. T. McDaniel, and A. J. McAllister. 2002. Trends in reproductive performance in southeastern Holstein and Jersey DHI herds. J. Dairy Sci. 85:244-251.

Windig, J. J., M. P. L. Calus, and R. F. Veerkamp. 2005. Influence of herd environment on health and fertility and their relationship with milk production. J. Dairy Sci. 88:335-347. 